\title{
Study on Viscosity Reducer Flooding Technology for Deep Low Permeability Extra Heavy Oil Reservoirs
}

\author{
Xiaopeng Cao, ${ }^{1,2}$ Zupeng Liu ${ }^{(D},{ }^{2}$ Yong Yang, ${ }^{2}$ Shiming Zhang, ${ }^{3}$ Yahui Bu, ${ }^{2}$ Sen Wang, \\ Yipu Liang, ${ }^{1}$ and Qihong Feng ${ }^{1}{ }^{1}$ \\ ${ }^{1}$ School of Petroleum Engineering, China University of Petroleum (East China), Shandong Province Qingdao 266580, China \\ ${ }^{2}$ Exploration and Development Research Institute, Shengli Oilfield Company, SINOPEC, Dongying, \\ 257015 Shandong Province, China \\ ${ }^{3}$ Shengli Oil Production Company, Shengli Oilfield Company, SINOPEC, Dongying, 257015 Shandong Province, China
}

Correspondence should be addressed to Zupeng Liu; liuzupeng@outlook.com and Qihong Feng; fengqihong.upc@gmail.com

Received 10 February 2021; Revised 19 March 2021; Accepted 21 April 2021; Published 12 May 2021

Academic Editor: Qingwang Yuan

Copyright ( 2021 Xiaopeng Cao et al. This is an open access article distributed under the Creative Commons Attribution License, which permits unrestricted use, distribution, and reproduction in any medium, provided the original work is properly cited.

Deep low permeability extra heavy oil reservoir has the characteristics of high formation pressure, high crude oil viscosity, and low permeability. Conventional steam injection thermal recovery has poor viscosity reduction performance and low productivity of a single well, which makes it difficult to develop this type of heavy oil reservoir. In this paper, core flooding experiment and microvisualization equipment were used to study the mechanism of improving the recovery of deep extra heavy oil by using water-soluble viscosity reducer; the realization of water-soluble viscosity reducer in numerical simulation was achieved by using nonlinear mixing rule; the reservoir numerical simulation model of water-soluble viscosity reducer displacement in test well group was established to optimize the development technical parameter of water-soluble viscosity reducer. The results show that compared with waterflooding, the oil displacement efficiency of water-soluble viscosity reducer is increased by $12.7 \%$; watersoluble viscosity reducer can effectively reduce the viscosity of extra heavy oil, under the same temperature and permeability, the higher the concentration of viscosity reducer, the better the viscosity reduction effect, and the smaller the pressure gradient required at the same injection rate; the main mechanism of water-soluble viscosity reducer for enhancing oil recovery is to form oil in water emulsion, which can reduce the viscosity and interfacial tension of crude oil and reduce the residual oil saturation; in the pilot well group, the optimized injection concentration of water-soluble viscosity reducer is $3 \%$, and the optimal injection amount of water-soluble viscosity reducer solution is $50 \mathrm{t} / \mathrm{d}$; water-soluble viscosity reducer displacement was implemented in the pilot well group, the average daily oil of well group was increased from $1.8 \mathrm{t} / \mathrm{d}$ to $7.34 \mathrm{t} / \mathrm{d}$, and the pilot well group has achieved good development performance.

\section{Introduction}

Deep low permeability extra heavy oil reservoirs refer to the oil reservoirs with buried depth more than $2200 \mathrm{~m}$, reservoir permeability lower than $300 \mathrm{md}$, and crude oil viscosity greater than $10000 \mathrm{mPa} \cdot \mathrm{s}$ at $50^{\circ} \mathrm{C}$. Deep low permeability extra heavy oil reservoirs have the characteristics of deep burial depth, high formation pressure, low permeability, and poor crude oil fluidity, which leads to great difficulty in development and low productivity of a single well [1-10]. At present, there is no clear and reasonable development method for the economic and effective production of this type of heavy oil reservoir. The effective development of deep low permeability extra heavy oil is mainly restricted by two factors: one is the high reservoir pressure caused by deep burial depth; the other is the difficulty of flow caused by low permeability and high viscosity of crude oil [11-18].

High reservoir pressure leads to high surface steam injection pressure; when the injection pressure exceeds the critical steam pressure $(22.07 \mathrm{MPa})$, saturated steam with a certain dryness will become liquid-phase high-pressure hot water. For example, the enthalpy of saturated steam with $40 \%$ dryness is $853 \mathrm{~kJ} / \mathrm{kg}$, while that of high-pressure hot water is only $1.15 \mathrm{~kJ} / \mathrm{kg}$. The specific volume of saturated steam with $40 \%$ 
dryness is $2033 \mathrm{~L} / \mathrm{kg}$, while that of high-pressure hot water is only $4.41 \mathrm{~L} / \mathrm{kg}$. Because the enthalpy and specific volume of liquid-phase high-pressure hot water are far less than that of gas-phase saturated steam, its viscosity reduction radius is obviously weaker than that of steam, which leads to the difficulty of viscosity reduction by conventional steam thermal in deep low-permeability heavy oil reservoirs. Due to the dual influence of high crude viscosity and low reservoir permeability, it is difficult for crude oil to flow under initial formation conditions. During heavy oil cold production development, the limit oil drainage radius is less than $10 \mathrm{~m}$ $[13,19-23]$. Therefore, how to improve heavy oil flow capacity has become one of the key technologies for effective development of deep low permeability heavy oil reservoirs.

In order to improve the development performance of deep low permeability extra heavy oil reservoirs, the research of viscosity reducer flooding has been started gradually which mainly focuses on the huff and puff of water-soluble viscosity reducer, the mechanism of improving recovery, and the development technology [17, 24-27]. In the past, a watersoluble viscosity reducer was used in the near-wellbore reservoir for plugging removal; on the other hand, it was used as an auxiliary in thermal oil recovery [18, 28, 29]. However, there are few research and field applications of extra heavy oil reservoirs using viscosity reducer flooding at present. This paper studies the mechanism and field application effect of viscosity reducer flooding in deep low permeability extra heavy oil reservoirs from three aspects of physical simulation, numerical simulation, and field application.

\section{Experiments}

2.1. Experimental Apparatus and Materials. Experimental apparatus includes interface tensiometer, Brookfield viscometer, electric mixer, dehydration apparatus, stirrer, core displacement experiment device (including sand pack, pump, back pressure valve, the middle container, incubator, constant speed and pressure pump, electronic balance, and timer), microscopic simulation model of glass etching, and digital microscopic camera system.

The experimental oil is from Es 4 formation in Wang 152 block of Shengli Oilfield, viscosity of degassed crude oil at $50^{\circ} \mathrm{C}$ is $16840 \mathrm{mPa} \cdot \mathrm{s}$, and oil density is $0.9689 \mathrm{~g} / \mathrm{cm}^{3}$. The experimental water is also from Es $4^{4}$ formation in Wang 152 block, which is calcium chloride type, and the mineralization degree is $30432 \mathrm{mg} / \mathrm{L}$. The water-soluble viscosity reducer was composed of $0.3 \%$ anionic surfactant $\mathrm{XJ}+0.2 \%$ nonionic emulsifying viscosity reducer $\mathrm{OP}-10$. XJ is a new viscosity reducer synthesized by the oxidation reaction and sulfonation reaction. The water-soluble viscosity reducer is a homogeneous liquid without impurities and with a pungent smell. The $\mathrm{pH}$ value is about 7.0, and it is soluble in water without precipitation. The content of organic chlorine is 0 , the natural sedimentation dehydration rate is $92 \%$, and the washing oil rate is $86 \%$. The basic parameters of a watersoluble viscosity reducer are listed in Table 1 . The basic parameters of a water-soluble viscosity reducer are as follows: when the mass fraction is $3 \%$, the viscosity reduction rate is $82.1 \%$, and the interfacial tension is $0.34 \mathrm{mN} / \mathrm{m}$.

\subsection{Experiment Methods}

2.2.1. Oil Displacement Experiment. In order to analyze and compare the oil displacement efficiency of waterflooding and viscosity reducer flooding, two groups of viscosity reducer and waterflooding core displacement experiments were carried out. The experimental setup is shown in Figure 1. According to the actual formation parameters of Wang 152 block, in order to compare the development effects of different displacement methods, two sand packs were made; the core parameters are shown in Table 1. The experimental steps are as follows: (1) the core was vacuumed and injected with formation water until continuous water drops appear at the outlet of the core; (2) the saturated water in the core was replaced by experimental oil until continuous oil drops appear at the outlet of the core; (3) No.1 core was injected with formation water to drive oil, and the injection rate is $0.25 \mathrm{~mL} / \mathrm{min}$ until the water cut is above $98 \%$; (4) in No. 2 core, 3\% viscosity reducer was used for oil displacement, and the injection rate was consistent with step (3) until the water cut was above 98\%; (5) the formation waterflooding and viscosity reducer flooding with different mass fractions were carried out, respectively. When the water cut was above $98 \%$, the experiment was finished, and the injection pressure, oil production rate, and water production rate at different times in the displacement process were recorded.

2.2.2. Heavy Oil Seepage Experiment. The laboratory core displacement test is a direct method to determine the starting pressure gradient by establishing a certain pressure difference at both ends of the core and measuring the pressure difference and flow rate under the stable condition of the system. After obtaining the seepage curve of the core, then calculate the starting pressure gradient.

The experimental steps are as follows: (1) make sand packs with different permeability, and the core parameters are shown in Table 2; (2) the experimental crude oil was injected into the core, and different flow rates were used for displacement and pressure difference and flow rate were recorded, and the relationship curve of starting pressure gradient with flow rate was drawn; (3) mix experimental oil with viscosity reducer by various concertation and injected into the core; step (2) was repeated.

2.2.3. Microscopic Visualization Experiment. The experimental flow experiment is shown in Figure 2. The microvisualization experimental equipment mainly includes a microglass etching model (the appearance size is $50 \mathrm{~mm} \times 50 \mathrm{~mm}$, the pore diameter is $30-40 \mu \mathrm{m}$, and the permeability is about $150 \mathrm{mD}$ ), constant speed injection pump, and digital micro camera system, and the experimental temperature is $76^{\circ} \mathrm{C}$.

Experimental steps are as follows: (1) connect the experimental device according to the experimental flow chart, and inject formation water into the microscopic glass etching model with the flow rate of $0.03 \mathrm{~mL} / \mathrm{min}$, until the water phase distribution of the model is uniform and continuous water drops appear at the outlet end; (2) the experimental oil was injected into the microscopic glass etching model until the oil phase distribution in the model is 
TABLe 1: Core data table.

\begin{tabular}{lcccccc}
\hline \multirow{2}{*}{ Core number } & $\begin{array}{c}\text { Saturated water volume } \\
\mathrm{mL}\end{array}$ & $\begin{array}{c}\text { Total volume } \\
\mathrm{mL}\end{array}$ & $\begin{array}{c}\text { Porosity } \\
\%\end{array}$ & $\begin{array}{c}\text { Permeability } \\
\mathrm{mD}\end{array}$ & $\begin{array}{c}\text { Saturated oil volume } \\
\mathrm{mL}\end{array}$ & $\begin{array}{c}\text { Irreducible water saturation } \\
\%\end{array}$ \\
\hline 1 & 27.9 & 98.4 & 28 & 135 & 19.3 & 30.7 \\
2 & 27.6 & 98.4 & 28 & 140 & 19.6 & 28.8 \\
3 & 27.8 & 98.4 & 28 & 137 & 19.9 & 28.6 \\
4 & 28.7 & 98.4 & 29 & 153 & 21.1 & 26.4 \\
5 & 28.2 & 98.4 & 29 & 145 & 21.0 & 25.6 \\
6 & 28.9 & 98.4 & 29 & 154 & 21.2 & 26.8 \\
\hline
\end{tabular}

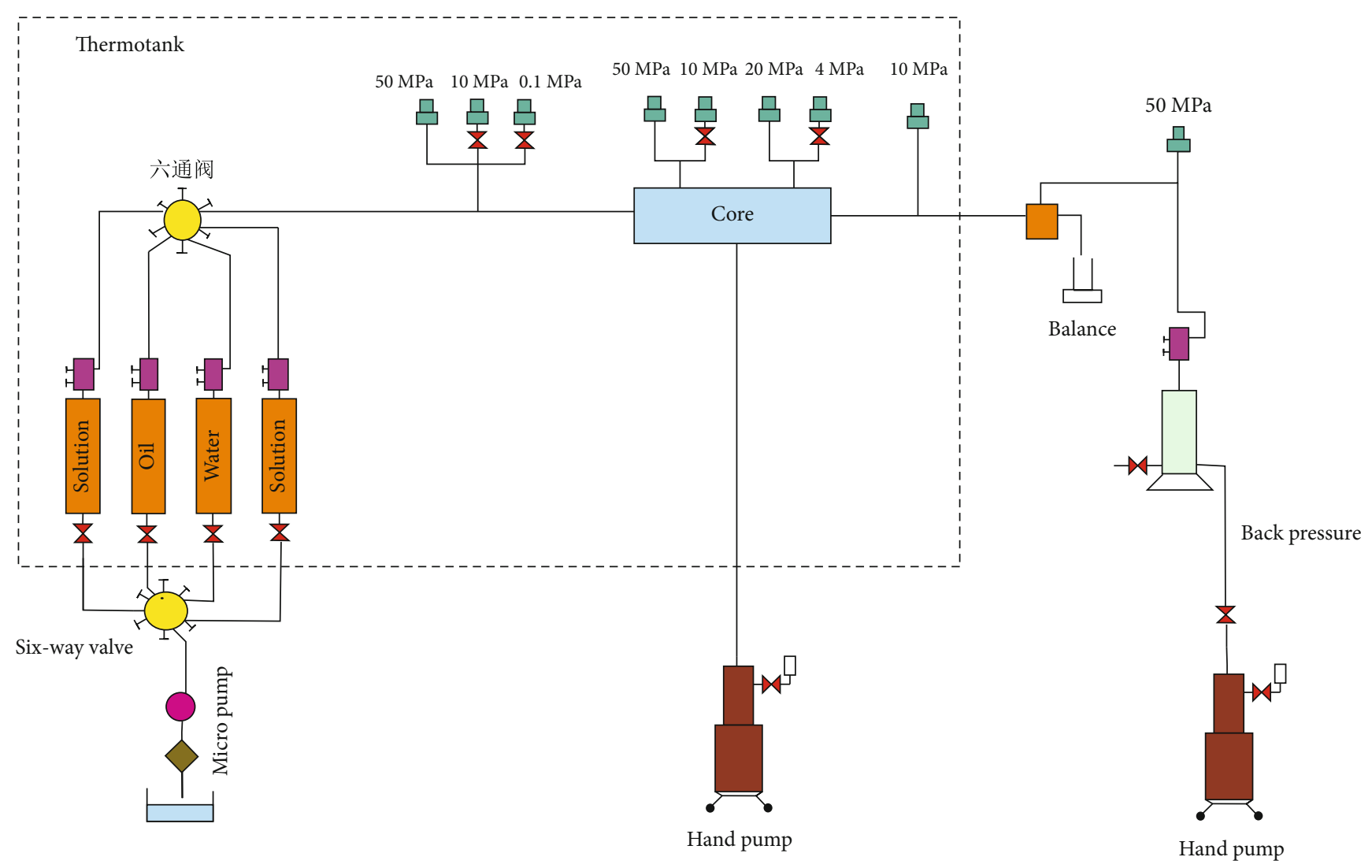

Figure 1: Schematic of the coreflooding unit.

TABle 2: Core data table.

\begin{tabular}{lcccccc}
\hline Core number & $\begin{array}{c}\text { Saturated water volume } \\
\mathrm{mL}\end{array}$ & $\begin{array}{c}\text { Total volume } \\
\mathrm{mL}\end{array}$ & $\begin{array}{c}\text { Porosity } \\
\%\end{array}$ & $\begin{array}{c}\text { Permeability } \\
\mathrm{mD}\end{array}$ & $\begin{array}{c}\text { Saturated oil volume } \\
\mathrm{mL}\end{array}$ & $\begin{array}{c}\text { Irreducible water saturation } \\
\%\end{array}$ \\
\hline 7 & 27.4 & 98.4 & 28 & 145 & 19.3 & 29.3 \\
8 & 25.6 & 98.4 & 26 & 41 & 18.0 & 29.8 \\
9 & 28.5 & 98.4 & 29 & 149 & 19.8 & 30.5 \\
10 & 26.6 & 98.4 & 27 & 42 & 18.5 & 30.4 \\
11 & 28.3 & 98.4 & 29 & 141 & 20.0 & 29.1 \\
12 & 25.6 & 98.4 & 26 & 10 & 17.9 & 30.1 \\
\hline
\end{tabular}

uniform and continuous oil drops appear at the outlet end; (3) inject formation water into the microscopic glass etching model with saturated oil until water cut at the outlet reaches 98\%; (4) inject viscosity reducer into the microscopic glass etching model until there is no oil dripping out at the outlet end. 


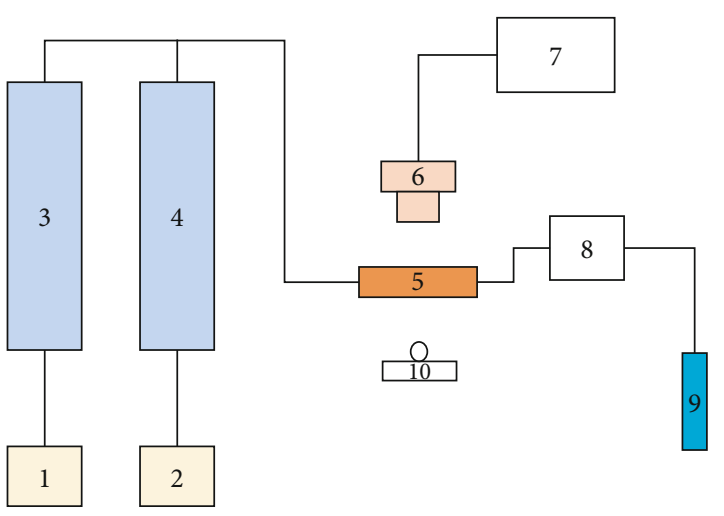

1,2-Constant speed injection pump;

3,4-Container;

5-Micro etching model;

6-Camera;

7-Computer;

8-Back pressure valve;

9-Measuring cylinder;

10-Light source

Figure 2: Microscopic visualization experiment flow.

\section{Results}

3.1. Effect of Viscosity Reducer Flooding on Oil Displacement Efficiency. According to the model experiment of sand pack flooding, the core oil displacement effect of waterflooding and viscosity reducer drive is compared in Figure 3. Compared with waterflooding, viscosity reducer flooding can slow down the rising speed of water cut. When displacement volume is $1.5 \mathrm{pv}$, the water cut of viscosity reducer flooding is $93 \%$ and that of waterflooding is $98.6 \%$, and the water cut of viscosity reducer flooding is $5.6 \%$ lower than that of waterflooding. At the same time, the viscosity reducer can greatly improve the oil displacement efficiency. Under the same displacement $(10 \mathrm{pv})$, the oil displacement efficiency of viscosity reducer is $20.1 \%$ higher than that of waterflooding, and the final oil displacement efficiency of waterflooding is $35.2 \%$, the oil displacement efficiency of viscosity reducer is $47.9 \%$, and the displacement efficiency is increased by $12.7 \%$.

It can be seen from Figure 4 that injection pressure decreased gradually because of high oil-water viscosity ratio, the water cut reached $80 \%$ in the initial stage of waterflooding, and the injection pressure was $7.3 \mathrm{MPa}$ in the initial stage. With the breakthrough of injected water, water channeling channels are formed in the core, and the core flow resistance decreases continuously, so the injection pressure drops until the end of displacement. In the process of viscosity reducer flooding, the oil-water viscosity ratio is reduced due to viscosity reduction, so the initial water cut is less than $40 \%$, and the water cut is lower than $60 \%$. With the injection of viscosity reducer, the injection pressure also decreases. When the water cut reaches $80 \%$, the injection pressure of viscosity reducer flooding is $4.8 \mathrm{MPa}$, and the injection pressure is obviously lower than that of waterflooding.

3.2. Influence of Viscosity Reducer Concentration. Slug concentration is an important index to evaluate the economic benefit of viscosity reducer. Four core displacement experiments were carried out with $1.0 \%, 3.0 \%, 5.0 \%$, and $6.0 \%$ viscosity reducer solutions. It can be seen from Table 3 that when the mass fraction of viscosity reducer is $1.0 \%$, the increment of oil recovery is small, because less water-soluble viscosity reducer is injected in the displacement process, and less oil in water emulsion is generated due to the influence of core adsorption, so the viscosity reduction effect is not ideal; when the mass fraction of viscosity reducer is greater than $1.0 \%$, the oil recovery increases with the increase of its mass fraction. Because of the increase of viscosity reducer mass fraction, the oil in water emulsion generated by core reaction increases, the fluidity of crude oil is stronger, the degree of residual oil production is improved, and the heavy oil recovery is improved.

3.3. Study on Seepage Law of Heavy Oil. It can be seen from Figure 5 that permeability, temperature, and viscosity reducer concentration have great influence on the flow law of heavy oil. When the core permeability is about $145 \mathrm{md}$, the starting pressure gradient of heavy oil at $76^{\circ} \mathrm{C}$ and $150^{\circ} \mathrm{C}$ is 0.363 and $0.020 \mathrm{MPa} / \mathrm{cm}$, respectively. Secondly, the pressure gradient increases with the decrease of permeability. Taking $150^{\circ} \mathrm{C}$ as an example, the starting pressure gradient of $145 \mathrm{md}$ core is $0.020 \mathrm{MPa} / \mathrm{cm}$, and that of $50 \mathrm{md}$ is $0.028 \mathrm{MPa} / \mathrm{cm}$. When the core permeability is $145 \mathrm{md}$ and the experimental temperature is $150^{\circ} \mathrm{C}$, the start-up pressure gradient of extra heavy oil is $0.02027 \mathrm{MPa} / \mathrm{cm}$; when $3 \%$ viscosity reducer is added, the starting pressure gradient is reduced to $0.01014 \mathrm{MPa} / \mathrm{cm}$; when $6 \%$ viscosity reducer is added, the starting pressure gradient is almost 0 .

At the same time, when the pressure gradient is small, there is a concave nonlinear section in the velocity pressure gradient curve, and the viscous oil seepage is nonlinear. When the pressure gradient reaches a certain value, it changes into a straight line. After adding viscosity reducer, the concave nonlinear section under low-pressure gradient gradually disappears, and the fluidity of heavy oil is obviously improved. In the same core, the lower the temperature, the longer the nonlinear seepage section. A water-soluble viscosity reducer has a good viscosity reduction effect. At the same temperature and permeability, the higher the viscosity reducer concentration is, the better the viscosity reduction performance is. The smaller the pressure gradient is at the same injection rate, the more the flow rate differential pressure curve moves to the left, and the smaller the starting pressure of heavy oil is. The higher the viscosity reducer concentration is, the shorter the nonlinear section of the curve is, and the smaller the pressure gradient required to reach the quasilinear flow is.

3.4. Microscopic Visualization Experiment. During the process of waterflooding, due to the high viscosity and high flow resistance of heavy oil, the cross-flow channel between the injection end and the production end is formed, resulting in uneven sweep and small sweep range. The main occurrence modes of residual oil are residual oil not swept, remaining oil block after sweep, and residual oil film covering the surface of sand particles. These three modes cause high residual oil saturation and low oil displacement efficiency. 


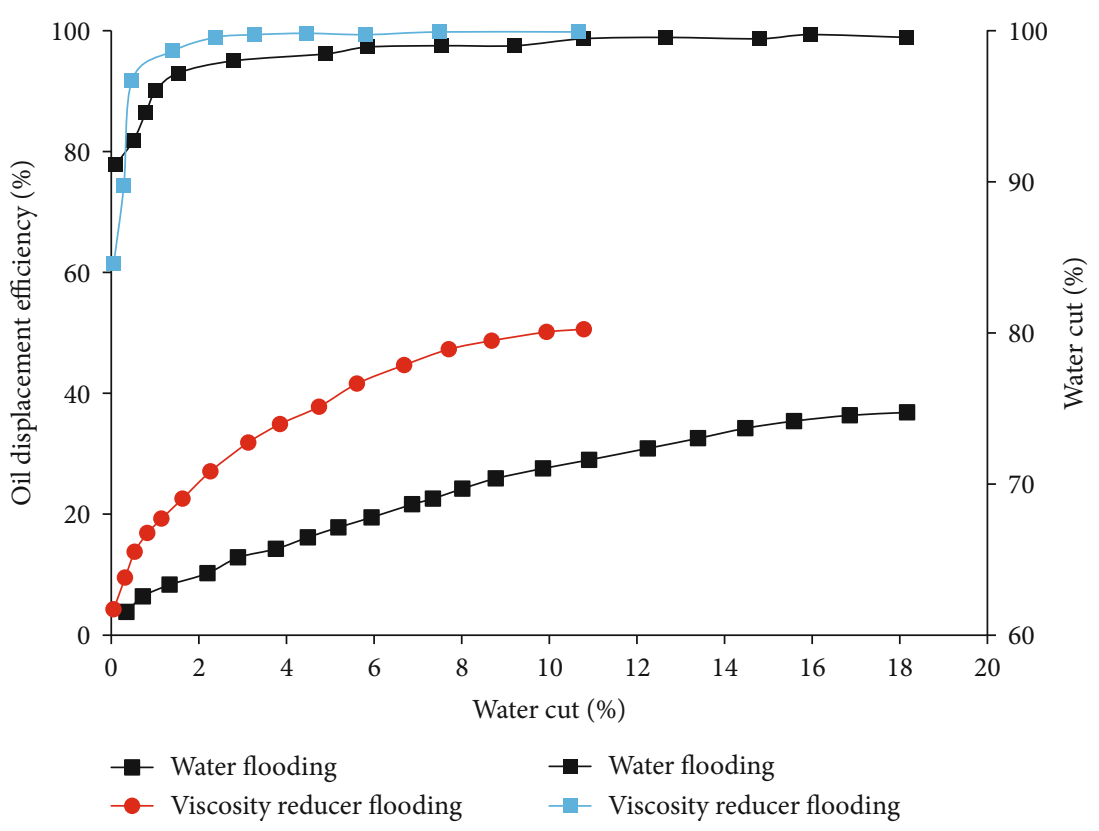

FIGURE 3: Oil displacement efficiency and water cut curve of sand packs under different methods.

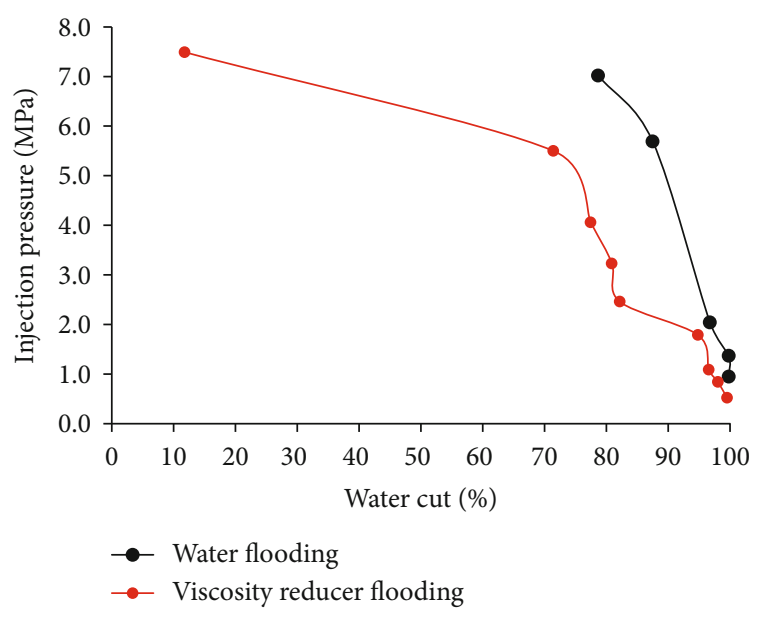

FIGURE 4: The relationship between injection pressure and water cut for waterflooding and viscosity reducer flooding.

Figure 6 shows the distribution of remaining oil under different displacement modes. After waterflooding, the large oil block in Figure 6(a) between pores formed a few smaller oil droplets in Figure 6(b) after water-soluble viscosity reducer flooding. This is mainly because the gum and asphaltene in the heavy oil are natural emulsifiers, which make the crude oil easier to form w/o emulsion and difficult to flow. A water-soluble viscosity reducer can change w/o emulsion into o/w emulsion, and large oil drops can be changed into small oil droplets, which makes it easier for crude oil to pass through the pore throat. Secondly, due to the low viscosity of continuous phase water, the friction between oil films is changed into internal friction between water films during the flow process, which greatly reduces the flow resistance and fluid viscosity.
Figures 6(c) and 6(d) show that the direction of capillary force is consistent with the displacement direction, and the capillary force changes from resistance to power, thus displacing residual oil between particles under the action of capillary force. This is mainly due to the low interfacial tension formed between water-soluble viscosity reducer and heavy oil, which changes the contact angle of oil-water interface, improves the interfacial properties of oil droplets, and makes oil droplets reduce viscosity in water solubility Secondly, the decrease of oil-water interfacial tension leads to a higher capillary number. The larger the capillary number is, the lower the residual oil saturation is, so the recovery rate of heavy oil is improved.

The main modes of remaining oil occurrence are the remaining oil not swept by waterflooding, the remaining oil block in the scope of waterflooding, and the residual oil film covered on the surface of particles. These three modes result in high residual oil saturation and low oil displacement efficiency. Compared with waterflooding, during viscosity reducer flooding, due to the low viscosity of viscosity reducer solution, the sweep area did not change significantly, but the oil content in the affected area was significantly reduced and the oil washing efficiency was significantly improved. This is mainly because the viscosity reducer can form a stable oil in water emulsion, reduce the crude oil viscosity, and increase the crude oil fluidity. It is the ultralow interfacial tension formed between viscosity reducer and heavy oil, which can obtain higher capillary number, thus displacing residual oil between particles under the action of capillary force, reducing residual oil saturation, thus displacing more heavy oil.

\section{Numerical Simulation Study}

4.1. Model Description. According to the geological structure characteristics and fluid properties of a pilot test, the 3D 
TABLE 3: Table of oil production performance.

\begin{tabular}{lccccc}
\hline $\begin{array}{l}\text { Core } \\
\text { number }\end{array}$ & $\begin{array}{c}\text { Original oil } \\
\text { saturation } \\
\%\end{array}$ & $\begin{array}{c}\text { Waterflooding } \\
\text { recovery } \\
\%\end{array}$ & $\begin{array}{c}\text { Mass fraction of viscosity } \\
\text { reducer } \\
\%\end{array}$ & $\begin{array}{c}\text { Viscosity reducer flooding } \\
\text { recovery } \\
\%\end{array}$ & $\begin{array}{c}\text { Ultimate } \\
\text { recovery } \\
\%\end{array}$ \\
\hline 3 & 71.4 & 33.5 & 1.0 & 10.6 & 44.1 \\
4 & 73.6 & 34.2 & 3.0 & 12.4 & 46 \\
5 & 74.4 & 34.9 & 5.0 & 13.2 & 48.1 \\
6 & 73.2 & 35.8 & 6.0 & 13.9 & 49.7 \\
\hline
\end{tabular}

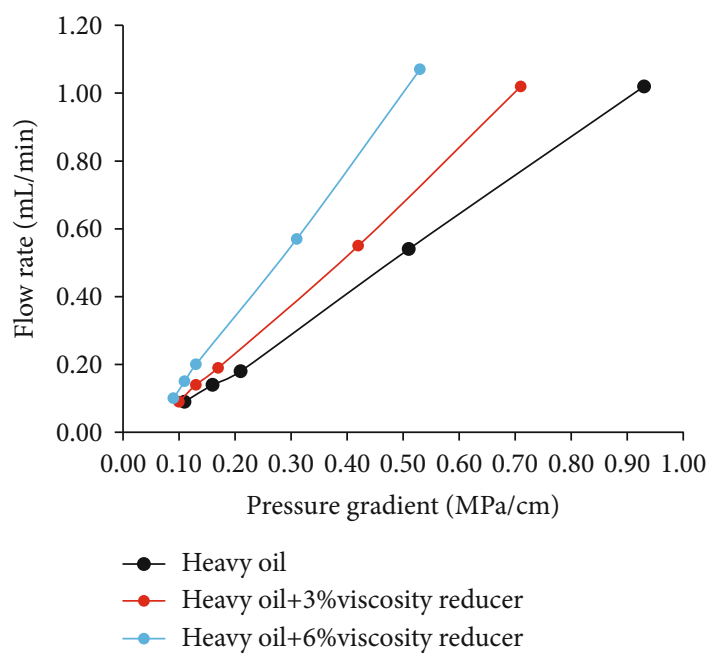

(a)

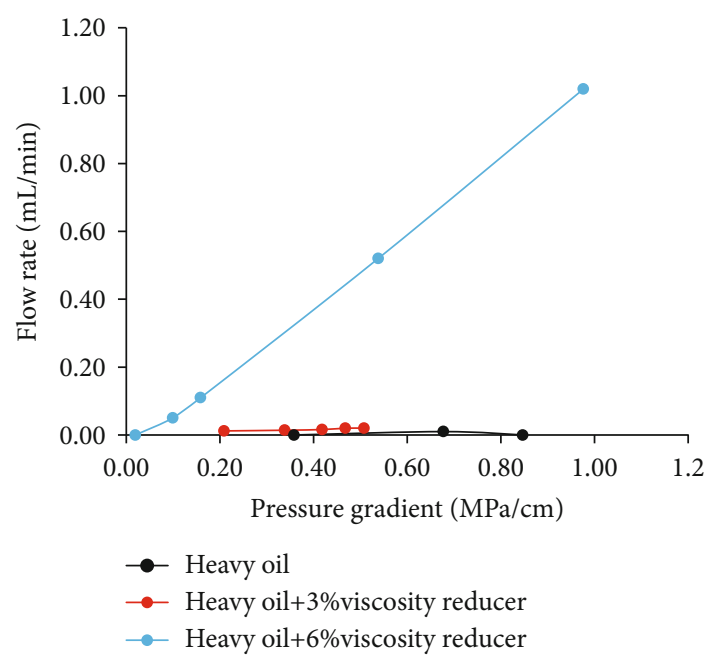

(c)

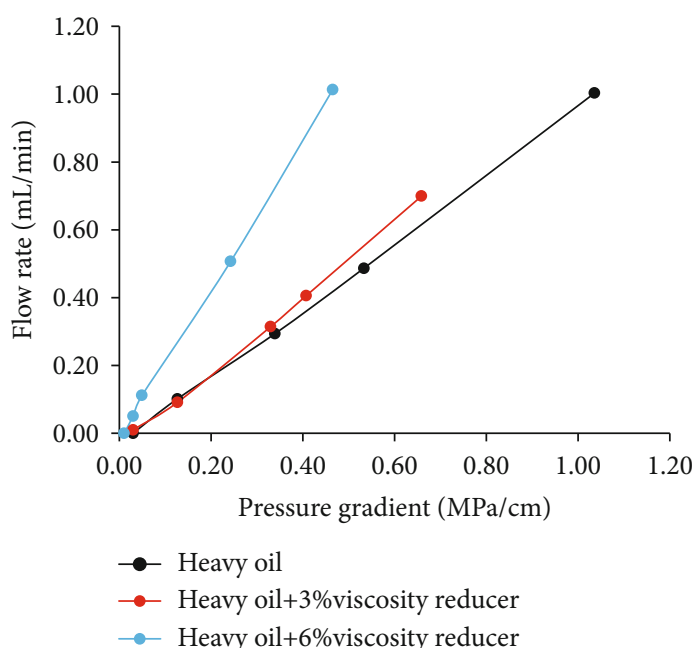

(b)

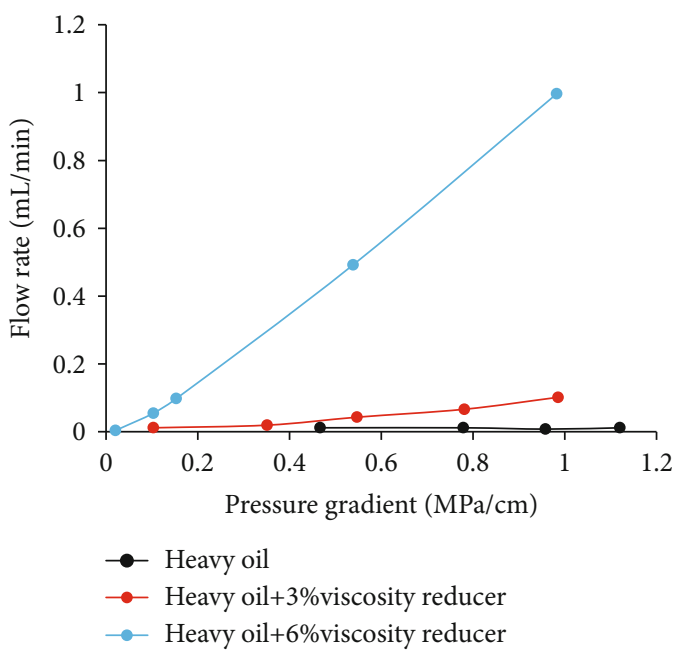

(d)

FIgURE 5: The relationship between flow rate and pressure gradient: (a) represent core flooding with $145 \mathrm{mD}$ and $150^{\circ} \mathrm{C}$; (b) represent core flooding with $40 \mathrm{mD}$ and $150^{\circ} \mathrm{C}$; (c) represent core flooding with $145 \mathrm{mD}$ and $76^{\circ} \mathrm{C}$; (d) represent core flooding with $40 \mathrm{mD}$ and $76^{\circ} \mathrm{C}$.

geological model shown in Figure 7 was established to provide the basis for the optimization design. The grid numbers in I direction, J direction, and $\mathrm{K}$ direction of the model are 127,63 , and 5, respectively. The plane grid step size is $10 \mathrm{~m}$, and there are 5 simulation layers in the longitudinal direction, and the total number of grids is 40005 . This simulation work was done by the STARS simulator in CMG software from the Computing Modeling Group. The rock properties and rock relative permeability data are shown in Tables 4 and 5 .

The viscosity of oil-in-water emulsion decreases nonlinearly with the increase of viscosity reducer solution concentration. In the initial period of viscosity reducer mass concentration, the viscosity decreases rapidly; while in the 


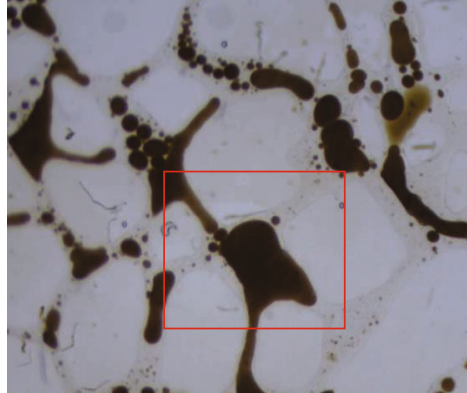

(a)

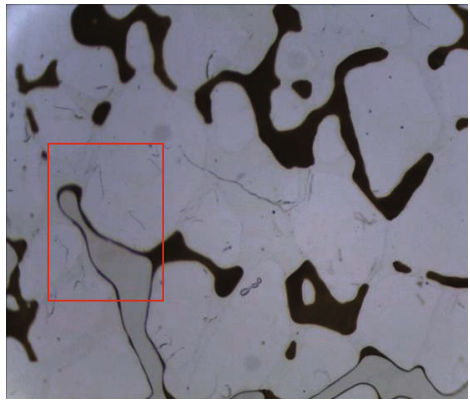

(c)

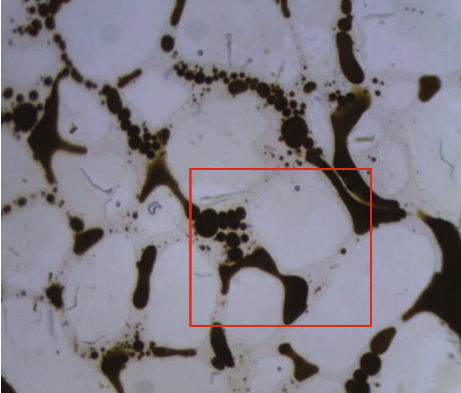

(b)

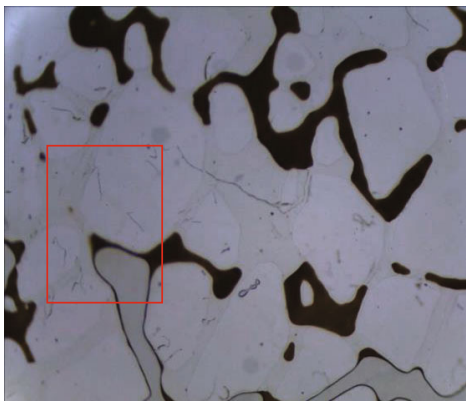

(d)

FIGURE 6: Remaining oil distribution under different displacement modes: (a) represent large oil block after waterflooding; (b) represent a few smaller oil droplets after viscosity reducer flooding; $(c, d)$ represent the direction of capillary force is consistent with the displacement direction.

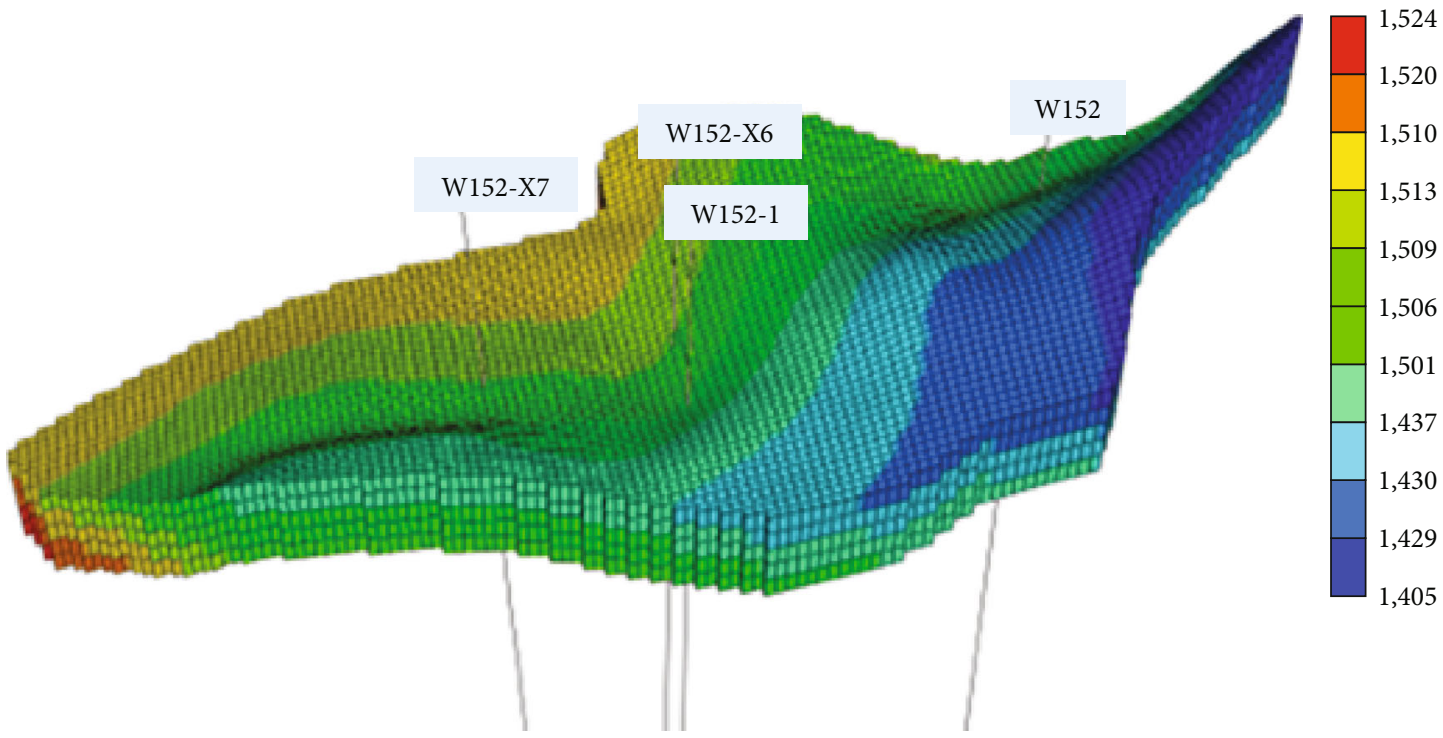

FIGURE 7: 3D geological model of the pilot test well group.

TABLE 4: Rock properties.

\begin{tabular}{lc}
\hline Rock compressibility $(1 / \mathrm{kPa})$ & $1.4 \times 10^{-5}$ \\
Rock heat capacity $\left(\mathrm{J} / \mathrm{m}^{3} \times{ }^{\circ} \mathrm{C}\right)$ & $2.34 \times 10^{-6}$ \\
Rock thermal conductivity $\left(\mathrm{J} /\left(\mathrm{m} \times\right.\right.$ day $\left.\left.\times{ }^{\circ} \mathrm{C}\right)\right)$ & $6.6 \times 10^{6}$ \\
Porosity (fraction) & 0.34 \\
Average permeability (Darcy) & 1.2 \\
\hline
\end{tabular}

later period of mass concentration, the viscosity decreases slowly. If the conventional linear mixing rule is adopted, the changing viscosity of the viscosity reducer cannot be accurately characterized. Therefore, the nonlinear mixing rule was used into the reservoir numerical simulation software. The correlation can be obtained by fitting the experimental emulsion viscosity results under different viscosity reducer concentrations. 
TABLE 5: Rock relative permeability data.

\begin{tabular}{lcc}
\hline Sw & Krw & Kro \\
\hline 0.45 & 0 & 1 \\
0.4716 & 0.0056 & 0.4793 \\
0.4986 & 0.0138 & 0.3567 \\
0.5256 & 0.0225 & 0.2488 \\
0.5526 & 0.0322 & 0.1874 \\
0.5796 & 0.044 & 0.1264 \\
0.6066 & 0.0591 & 0.067 \\
0.6336 & 0.0731 & 0.0318 \\
0.6606 & 0.0919 & 0.0175 \\
0.6876 & 0.1157 & 0.0063 \\
0.7038 & 0.1325 & 0.0015 \\
0.72 & 0.15 & 0 \\
\hline
\end{tabular}

$$
\begin{aligned}
\ln \left(\mu_{\alpha}\right) & =\sum_{i=1}^{n_{\epsilon \in S}} f\left(f_{\alpha_{i}}\right) \times \ln \left(\mu_{\alpha i}\right)+N \times \sum_{i=1}^{n_{\epsilon \in S}} f_{\alpha_{i}} \times \ln \left(\mu_{\alpha i}\right), \\
N & =\frac{1-\sum_{i=1}^{n_{i} \epsilon s} f\left(f_{a i}\right)}{\sum_{i=1}^{n_{c} \notin s} f_{a i}}
\end{aligned}
$$

where $N$ is the viscosity of water phase or oil phase, $\mu_{\alpha i}$ is the viscosity of component $i$ in water or oil, $f_{a i}$ is the weighting factor of nonkey component $i$ in water or oil, $f\left(f_{a i}\right)$ is the weighting factor of key component $i$ in water or oil, $n_{c} \in s$ is the number of key components in liquid, $n_{c} \notin s$ is the number of components excluding key components, and $N$ is the normalization factor.

By fitting the experimental results under different viscosity reducer concentrations, the nonlinear mixing rule is used to fit the oil-water viscosity after mixing, and the variation law of crude oil viscosity with viscosity reducer concentration is obtained [26]. The correlation was obtained by fitting the experimental emulsion viscosity results under different viscosity reducer concentrations. The fitting results are shown in Figure 8.

The influence of ultralow interfacial tension on capillary number, the adsorption of viscosity reducer, and the end point calibration of residual oil are considered in the numerical model. Finally, the numerical simulation of viscosity reducer flooding is realized. Three independent components of water, viscosity reducer, and crude oil are established in the fluid model, including water and viscosity reducer in the water phase. The nonlinear function of viscosity reducer component, reduction of residual oil saturation, and phase permeability curve interpolation are considered in the composition setting.

4.2. Optimization of Development Scheme. Based on laboratory viscosity reduction experiment fitting and pilot production history fitting, the development technology limit optimization of viscosity reduction flooding was carried out. The development index selected in the study is the net oil production of a single well after 5 years of simulated pro-

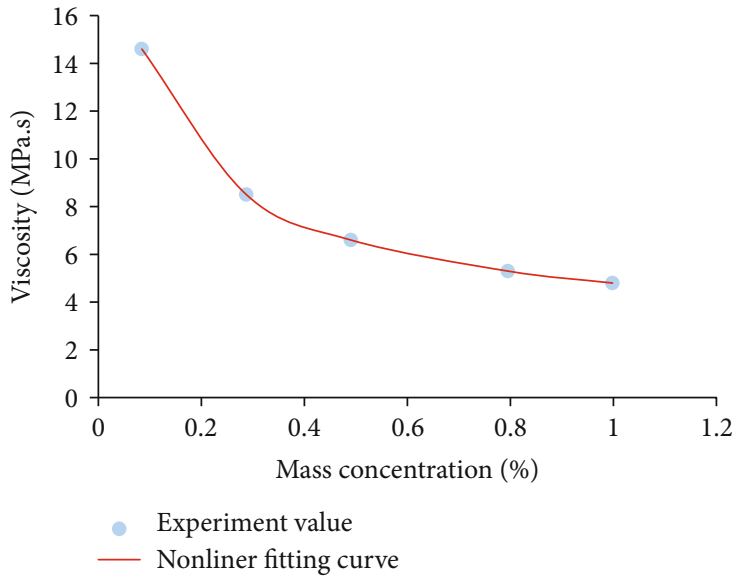

Figure 8: Crude oil viscosity change fitting curve.

duction, and the net oil production is calculated by the following equation:

$$
\mathrm{NetOil}_{\mathrm{cum}}=\mathrm{Oil}_{\mathrm{cum}}-\frac{C_{\text {inj }}}{p_{\mathrm{oil}}},
$$

where NetOil $l_{\text {cum }}$ is the net cumulative oil production per well, Oil ${ }_{\text {cum }}$ is the cumulative oil production per well, $C_{\text {inj }}$ is the cost of viscosity reducer, and $p_{\text {oil }}$ is the oil price.

4.2.1. Injection Concentration Optimization. Under the condition of keeping the injection volume of water-soluble viscosity reducer solution at $50 \mathrm{t} / \mathrm{d}$, the development effect of water-soluble viscosity reducer with mass concentration of $1 \%, 2 \%, 3 \%, 4 \%$, and $5 \%$ was compared by numerical simulation. It can be seen from Figure 9 that the net oil production of a single well increases first and then decreases with the increase of injection concentration. This is because the higher the concentration of water-soluble viscosity reducer is, the more oil in water emulsion can be formed in the reservoir, the lower the viscosity of crude oil, and the stronger the fluidity. However, increasing the amount of water-soluble viscosity reducer will increase the investment cost and reduce the net oil production of a single well. Therefore, the optimal injection concentration is $3 \%$.

4.2.2. Injection Volume Optimization. Under the condition of keeping the injection mass concentration of a water-soluble viscosity reducer at $3 \%$, the net oil production of a single well with water-soluble viscosity reducer solution injection volume of $20,30,40,50,60$, and $70 \mathrm{t} / \mathrm{d}$ is simulated. It can be seen from Figure 10 that the net oil production of a single well gradually increases with the increase of water-soluble viscosity reducer solution injection. When the injection amount exceeds $50 \mathrm{t} / \mathrm{d}$, the net oil production of a single well increases slowly. Considering the field injection capacity, the optimal injection volume of water-soluble viscosity reducer solution is $50 \mathrm{t} / \mathrm{d}$. 


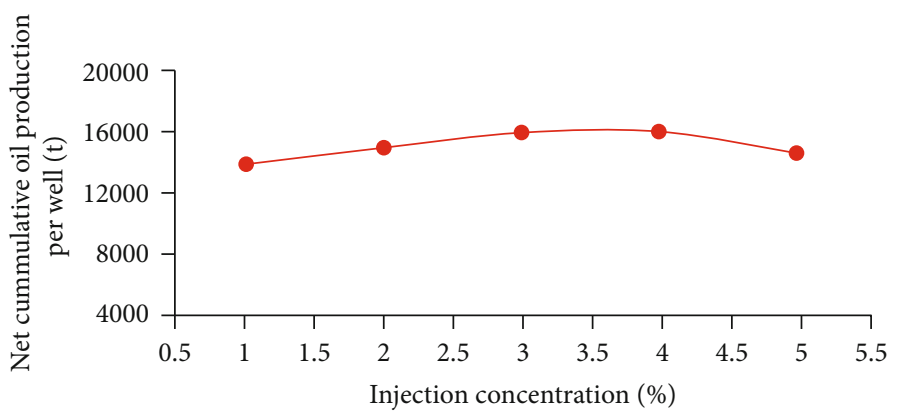

FIGURE 9: Relationship between net oil cumulative production and viscosity reducer concentration for a single well.

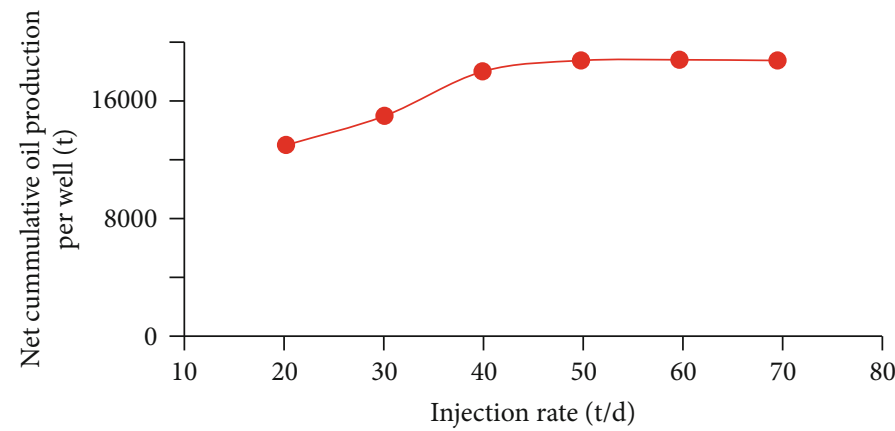

FIGURE 10: Relationship between net oil cumulative production and injection volume of viscosity reducer concentration for a single well.

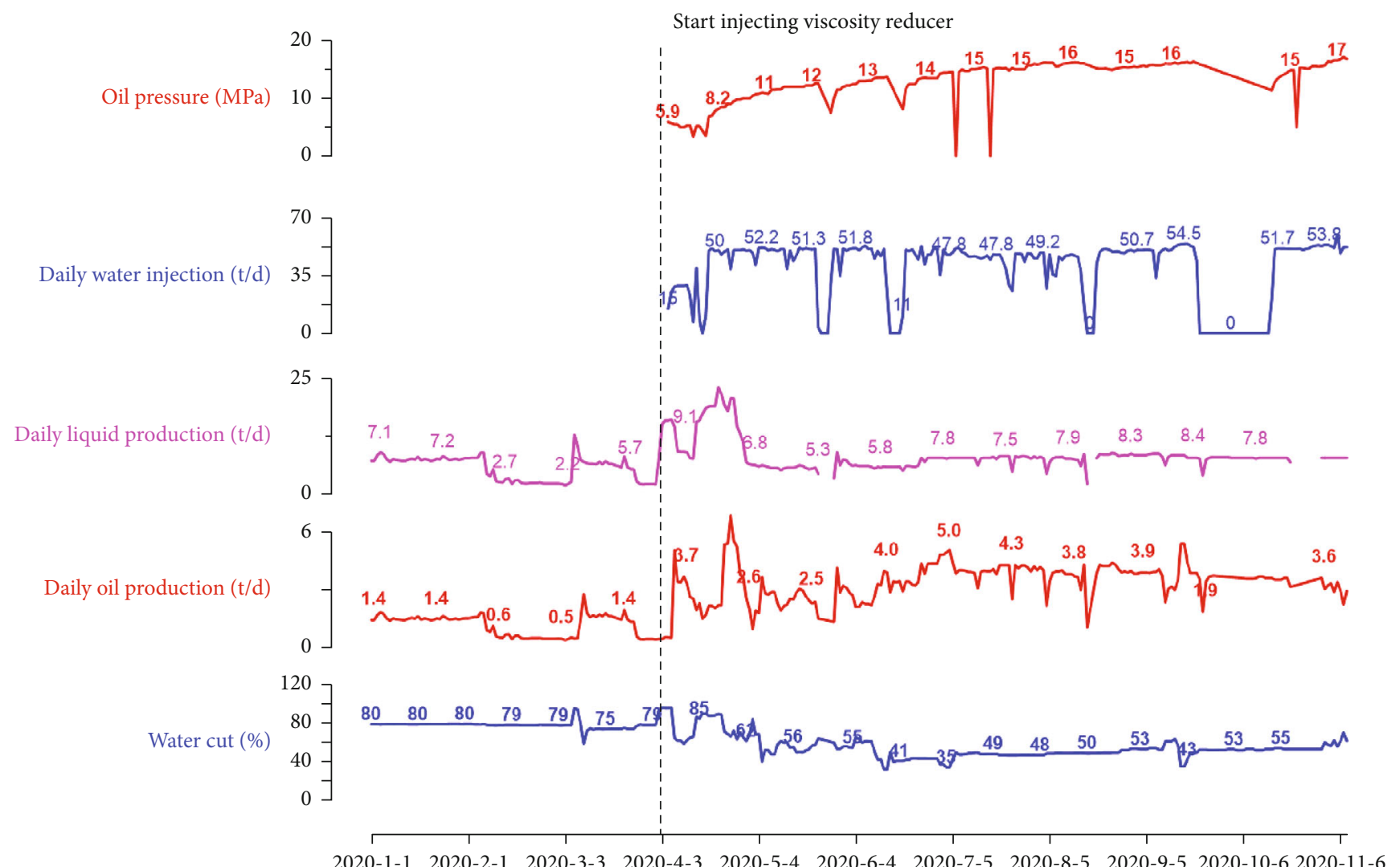

$2020-1-1 \quad 2020-2-1 \quad 2020-3-3 \quad 2020-4-3 \quad 2020-5-4 \quad 2020-6-4 \quad 2020-7-5 \quad 2020-8-5 \quad 2020-9-5 \quad 2020-10-6 \quad 2020-11-6$

Figure 11: Production curves in the W152-X6 pilot test. 


\section{Field Application}

The pilot test area of the W152-X6 well group is in Wang 152 block. The buried depth of the reservoir is $1530 \mathrm{~m}$, the formation temperature is $76^{\circ} \mathrm{C}$, the original reservoir pressure is $15.18 \mathrm{MPa}$, the average permeability is $137 \mathrm{mD}$, the average porosity is $27.4 \%$, and the shale content is $9.7 \%$. The surface crude oil density is $0.9689 \mathrm{~g} / \mathrm{cm}^{3}$, and the surface degassed oil viscosity is $16840 \mathrm{mPa} \cdot \mathrm{s}$ at $50^{\circ} \mathrm{C}$, its freezing point is $32^{\circ} \mathrm{C}$, and the high gum content is $40.08 \%$. The total salinity of formation water is $30432 \mathrm{mg} / \mathrm{L}$, of which the chloride ion content is $18083 \mathrm{mg} / \mathrm{L}$. Low formation permeability and high viscosity of crude oil under formation conditions lead to lower crude oil mobility and more difficult development.

Since 2003, the block has been developed mainly by steam stimulation, fracturing, and sand control, but the development effect is not good, and the recovery rate is only $0.8 \%$. At present, the daily liquid production of a single well in the well group is only $5.3 \mathrm{t} / \mathrm{d}$, the daily oil production of a single well is only $1.8 \mathrm{t} / \mathrm{d}$, and the water cut is $67.1 \%$. The development performance of the block is poor, so it is necessary to transform the economic and reasonable development mode to realize benefit development.

The W152-X6 well group in Wang 153 block is selected as the pilot test area to carry out the pilot test of viscosity reducer flooding for deep low permeability heavy oil reservoir, including 1 injection well and 3 oil producers. According to the production effect curve in Figure 11, after viscosity reducer flooding on April 3, 2020, the daily oil production in the test area increased from $1.8 \mathrm{t} / \mathrm{d}$ before to $7.34 \mathrm{t} / \mathrm{d}$, increased by 4.1 times, the maximum increased to $7.8 \mathrm{t} / \mathrm{d}$, and the daily liquid production increased by $14.7 \mathrm{t} / \mathrm{d}, 2.8$ times, and the highest can reach $17.7 \mathrm{t} / \mathrm{d}$ from $5.3 \mathrm{t} / \mathrm{d}$ before; the injection pressure of water well increases from $6 \mathrm{MPa}$ to $15 \mathrm{MPa}$ and keeps stable, which indicates that the viscosity of crude oil is reduced and the starting pressure gradient of crude oil is reduced after viscosity reducer flooding. The problem of low injection capacity of deep low permeability heavy oil is solved, and the heavy oil fluidity is increased; the seepage resistance is reduced, and the production effect is obviously improved.

\section{Conclusions}

(1) Compared with waterflooding, the oil displacement efficiency can be increased by $4.6 \%$ after watersoluble viscosity reducer flooding

(2) A water-soluble viscosity reducer can effectively reduce the viscosity of heavy oil. Under the same temperature and permeability conditions, the higher the viscosity reducer concentration, the better the viscosity reduction performance

(3) The main mechanism of a water-soluble viscosity reducer to enhance oil recovery is to form stable oil in water emulsion, reduce crude oil viscosity, and increase crude oil fluidity by ultralow interfacial tension formed between water-soluble viscosity reducer and heavy oil, which can obtain high capillary number and reduce residual oil saturation

(4) Using the nonlinear mixing rule, the characterization method of crude oil viscosity with the concentration of water-soluble viscosity reducer was obtained. By using the numerical simulation method, the injection concentration of a water-soluble viscosity reducer was $3 \%$, and the injection volume was $50 \mathrm{t} / \mathrm{d}$

(5) The field test shows that the daily oil production increases from $0.2 \mathrm{t} / \mathrm{d}$ before the measures to $4.4 \mathrm{t} / \mathrm{d}$, and the water cut decreases by $29.2 \%$ by watersoluble viscosity reducer flooding

\section{Data Availability}

Data will be made available on request.

\section{Conflicts of Interest}

The authors declare no conflicts of interest.

\section{Authors' Contributions}

Zupeng Liu, Qihong Feng, Yahui Bu, Sen wang, and Yipu Liang conducted the experiment work and wrote the manuscript. Shiming Zhang, Xiaopeng Cao, and Yong Yang conducted the simulations and analyzed the pilot production data, and all authors have read and approved the final manuscript.

\section{Acknowledgments}

This work is supported by the Basic Prospective Project of Sinopec (P20058-1-2) and by the National Science and Technology Planning Project of China (2016ZX05011-003) and Sinopec Scientific Research Project (P17003).

\section{References}

[1] L. Niño, F. Bonilla, L. Gil et al., "Successful strategy for waterflooding project implementation in an extra heavy oil field," in Proceedings of SPE Latin American and Caribbean Petroleum Engineering Conference, Virtual, p. 10, 2020.

[2] M. Urdaneta, E. Castellanos, and Y. E. Askoul, "Potential application of thermal processes to improve extra heavy oil recovery: a simulation numerical study from Orinoco Oil Belt, Boyaca Area," in Proceedings of SPE Heavy Oil Conference Canada, Calgary, p. 10, Alberta, Canada, 2012.

[3] Z. Yang, X. Li, H. Chen et al., "Development optimization for improving oil recovery of cold production in a foamy extraheavy oil reservoir," in Proceedings of SPE Oil and Gas India Conference and Exhibition, p. 17, Mumbai, India, 2019.

[4] A. Zolotukhin, "Advances in extra heavy oil development technologies (Zolotukhin)," in Proceedings of 20th World Petroleum Congress, p. 13, Doha, Qatar, 2011.

[5] Y. Zhang, H. Chen, X. Sun, X. Duan, W. Hu, and X. Zhang, "Optimization of thermal recovery strategies for offshore heavy oil reservoirs in Bohai Bay, China," Petroleum Science and Technology, vol. 34, no. 2, pp. 139-144, 2016.

[6] X. Li, L. Shi, H. Li, P. Liu, J. Luo, and Z. Yuan, "Experimental study on viscosity reducers for SAGD in developing extra- 
heavy oil reservoirs," Journal of Petroleum Science and Engineering, vol. 166, pp. 25-32, 2018.

[7] X. Han, L. Zhong, Y. Liu, J. Zou, and Q. Wang, "Study and pilot test of multiple thermal-fluid stimulation in offshore Nanpu oilfield," SPE Production \& Operations, vol. 35, no. 3, pp. 592-603, 2020.

[8] M. Yang, T. G. Harding, and Z. Chen, "Field-scale modeling of hybrid steam and in-situ-combustion recovery process in oilsands reservoirs using dynamic gridding," SPE Reservoir Evaluation \& Engineering, vol. 23, no. 1, pp. 311-325, 2020.

[9] S. Wang, Q. Feng, F. Javadpour, M. Zha, and R. Cui, "Multiscale modeling of gas transport in shale matrix: an integrated study of molecular dynamics and rigid-pore-network model," SPE Journal, vol. 25, no. 3, pp. 1416-1442, 2020.

[10] Z. Rui, X. Wang, Z. Zhang et al., "A realistic and integrated model for evaluating oil sands development with steam assisted gravity drainage technology in Canada," Applied Energy, vol. 213, pp. 76-91, 2018.

[11] Z. Rui, J. Lu, Z. Zhang et al., "A quantitative oil and gas reservoir evaluation system for development," Journal of Natural Gas Science and Engineering, vol. 42, pp. 31-39, 2017.

[12] J. Jiang, Z. Rui, R. Hazlett, and J. Lu, “An integrated technicaleconomic model for evaluating $\mathrm{CO}_{2}$ enhanced oil recovery development," Applied Energy, vol. 247, pp. 190-211, 2019.

[13] J. Wang and M. Dong, "Optimum effective viscosity of polymer solution for improving heavy oil recovery," Journal of Petroleum Science and Engineering, vol. 67, no. 3-4, pp. 155158, 2009.

[14] V. Alvarado and E. Manrique, "Enhanced oil recovery: an update review,” Energies, vol. 3, no. 9, pp. 1529-1575, 2010.

[15] M. Bagheripour Haghighi, S. Ayatollahi, and M. Shabaninejad, "Comparing the performance and recovery mechanisms for steam flooding in heavy and light oil reservoirs," in SPE Heavy Oil Conference Canada. Society of Petroleum Engineers, Canada, 2012.

[16] K. Guo, H. Li, and Z. Yu, "In-situ heavy and extra-heavy oil recovery: a review," Fuel, vol. 185, pp. 886-902, 2016.

[17] E. Shilov, A. Cheremisin, K. Maksakov, and S. Kharlanov, "Huff-n-puff experimental studies of $\mathrm{CO}_{2}$ with heavy oil," Energies, vol. 12, no. 22, pp. 4308-4898, 2019.

[18] B. Ren and I. Duncan, "Modeling oil saturation evolution in residual oil zones: implications for $\mathrm{CO} 2 \mathrm{EOR}$ and sequestration," Journal of Petroleum Science \& Engineering, vol. 177, pp. 528-539, 2019.

[19] A. A. El-Abbas and S. A. Shedid, "Experimental investigation of the feasibility of steam/chemical steam flooding processes through horizontal wells," in SPE Asia Pacific Oil and Gas Conference and Exhibition, Jakarta, Indonesia, 2001.

[20] D. Li, M. Y. Shi, D. Wang, and Z. Li, "Chromatographic separation of chemicals in alkaline surfactant polymer flooding in reservoir rocks in the Daqing oil field," in Spe International Symposium on Oilfield Chemistry, Texas, 2009.

[21] H. Shamekhi, A. Kantzas, J. L. Bryan, and S. Su, "Insights into heavy oil recovery by surfactant, polymer and ASP flooding.," in In Proceedings of SPE Heavy Oil Conference-Canada, pp. 11-13, Calgary, Alberta, Canada, June 2013.

[22] J. J. Sheng, B. Leonhardt, and N. Azri, "Status of polymerflooding technology," Journal of Canadian Petroleum Technology, vol. 54, no. 2, pp. 116-126, 2015.

[23] X. Han, L. Zhong, Y. Liu, Q. Wang, and C. Wang, "Experimental study of polyacrylamide polymer gel for profile controlling in high-temperature offshore reservoirs," Energy Sources Part A Recovery Utilization \& Environmental Effects, vol. 1, pp. 115, 2020.

[24] J. F. Mccafferty and G. G. Mcclaflin, "The field application of a surfactant for the production of heavy, viscous crude oils," in SPE Annual Technical Conference and Exhibition, Washington, D.C., 1992.

[25] P. Wang, F. Zhao, J. Hou, G. Lu, M. Zhang, and Z. Wang, "Comparative analysis of $\mathrm{CO}_{2}, \mathrm{~N}_{2}$, and gas mixture injection on asphaltene deposition pressure in reservoir conditions," Energies, vol. 11, no. 9, p. 2483, 2018.

[26] Z. Liu, G. Wu, and C. Wei, "Physical experiments and numerical simulations of viscosity reducer flooding for ordinary heavy oil," Journal of Petroleum Science \& Engineering, vol. 192, p. 107194, 2020.

[27] Z. Wang, M. Lin, S. Jin, Z. Yang, Z. Dong, and J. Zhang, "Combined flooding systems with polymer microspheres and nonionic surfactant for enhanced water sweep and oil displacement efficiency in heterogeneous reservoirs," Journal of Dispersion Science and Technology, vol. 41, no. 2, pp. 267276, 2020.

[28] J. A. Rocha, E. N. Baydak, H. W. Yarranton et al., "Role of aqueous phase chemistry, interfacial film properties, and surface coverage in stabilizing water-in-bitumen emulsions," Energy \& Fuels, vol. 30, no. 7, pp. 5240-5252, 2016.

[29] M. S. Kamal, I. A. Hussein, and A. S. Sultan, "Review on surfactant flooding: phase behavior, retention, IFT, and field applications," Energy \& Fuels, vol. 31, no. 8, pp. 7701-7720, 2017. 